$\begin{array}{lllllllllllll}\text { A C A } & \text { C H E M I A } & \text { S A N D I A V I A } & 12 & (1958) & 731-736\end{array}$

\title{
On the Reaction between Substituted Malonic Esters and Methylene Bromide. II
}

\author{
LE N N A R T EB ER S O N
}

Department of Organic Chemistry, Chemical Institute, University of Lund, Sweden

\begin{abstract}
$\alpha, \alpha, \omega, \omega$-Tetracarbethoxyalkanes of the type III with $\mathrm{n}=0,2,3$, in the form of their disodium compounds, react with methylene bromide in ethanolic solution with the formation of the tetraesters IV, $\mathrm{n}=0,2,3$. With III, $\mathrm{n}=1$, the reaction takes another course and mainly pentaethyl 1,1,3,3,5-pentacarboxylate (VI) is formed.
\end{abstract}

The reaction between the sodium compound of a monosubstituted malonic ester and methylene bromide in ethanolic solution has been found to proceed according to the formula ${ }^{1,2}$ :

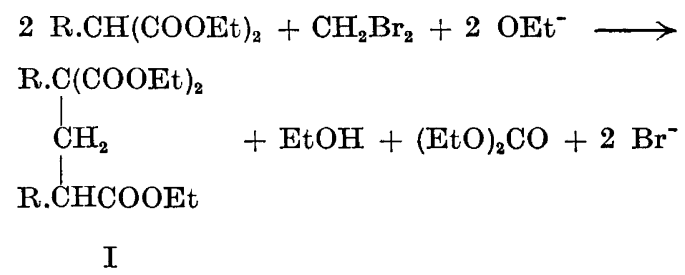

$\mathrm{I}$

for $\mathrm{R}=$ methyl, ethyl, $n$-propyl, isopropyl, $n$-butyl, isobutyl-, $n$-amyl, benzyl, trimethylsilylmethyl, and acetamino, i.e., one carbethoxy group is eliminated and a tricarboxylic ester (I) is formed. When $\mathrm{R}$ is an electronegative group, such as phenyl or carbethoxy, an $\alpha \alpha^{\prime}$-disubstituted glutaric ester (II) is formed directly with the elimination of two carbethoxy groups.

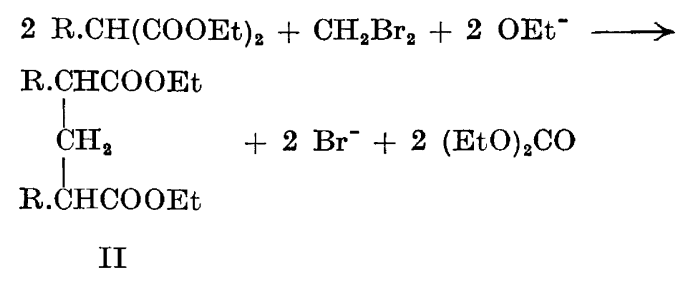

Acta Chem. Scand. 12 (1958) No. 4 
The investigation now has been extended to the study of the reaction between an $\alpha, \alpha, \omega, \omega$,-tetracarbethoxyalkane (III, $\mathrm{n}=0-3$ ) and methylene bromide.

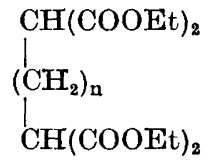

III

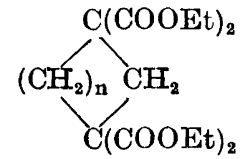

IV<smiles>CCOC(=O)C1CC2CC1C2</smiles>

V

Various examples of this reaction leading to cyclic compounds of the type IV are found in the literature. Kötz and Stalmann ${ }^{3}$ investigated the reaction between the disodium compound of 1,1,2,2,-tetracarbethoxyethane and methylene iodide at $130^{\circ}$ in absolute ethanol. They claimed that one solid (m. p. $43^{\circ}$ ) and one liquid form of tetraethyl cyclopropane-1,1,2,2-tetracarboxylate (IV, $\mathbf{n}=0$ ) were formed. They also stated that no reaction took place at temperatures below $130^{\circ}$ and that the exchange of methylene iodide for the corresponding chloride led to very poor yields.

Guthzeit and Dressel ${ }^{4}$ claimed that the main product from the reaction between 1,1,3,3-tetracarbethoxypropane (III, $\mathrm{n}=1$ ) and methylene iodide was tetraethyl cyclobutane-1,1,3,3-tetracarboxylate $(I V, n=1)$. However no proof of structure was given. Furthermore the same reaction with $1,1,4,4-$ tetracarbethoxybutane (III, $\mathrm{n}=2)^{5-8}$ and 1,1,5,5-tetracarbethoxypentane (III, $\mathrm{n}=3)^{9}$ has been shown to yield IV, $\mathrm{n}=2$ and 3 , respectively.

In view of the above results for alkylmalonic esters it seemed worth while to reinvestigate the cited reactions to establish whether a similar elimination of a carbethoxy group with the formation of $\mathrm{V}$ occurs parallel to the formation of IV.

1. The reaction between 1,1,2,2-tetracarbethoxyethane and methylene bromide (iodide). This reaction took place in boiling ethanolic solution both with the bromide and the iodide, contrary to the statement of Kötz and Stalmann ${ }^{3}$ that temperatures above $130^{\circ}$ were required to obtain reasonable yields. The product was distillable and consisted exclusively of tetraethyl cyclopropane$1,1,2,2$-tetracarboxylate with $\mathrm{m}$. p. $41-43^{\circ}$. No trace of diethyl carbonate, which would have resulted if a carbethoxy group had been eliminated, could be detected.

2. The reaction between 1,1,3,3-tetracarbethoxypropane and methylene bromide (iodide). If this reaction was carried out in boiling ethanolic solution (about $80^{\circ}$ ) with methylene bromide or iodide a very viscous oil was obtained. When distilled in vacuo it decomposed and the decomposition products smelt very strongly of diethyl methylenemalonate. Apparently the crude reaction product consisted of polymeric diethyl methylenemalonate to a great extent. On alkaline or acid hydrolysis only tarry products were obtained. However, if the reaction temperature was raised to $100^{\circ}$, the product was distillable and a main fraction boiling at $210-215^{\circ} / 4 \mathrm{~mm}$ was obtained. On acid hydrolysis it yielded an acid with m.p. 212-215 , which was identified as cyclohexane1,3,5-tricarboxylic acid. On alkaline hydrolysis an acid with m.p. $180-184^{\circ}$ (decomp.) was obtained, which lost carbon dioxide upon boiling with dilute 
hydrochloric acid and gave cyclohexane-1,3,5-tricarboxylic acid. The analyses indicated that the original ester was pentaethyl cyclohexane-1,1,3,3,5-pentacarboxylate (VI) and that the acid with m. p. 180-184 was cyclohexane1,1,3,3,5-pentacarboxylic acid.

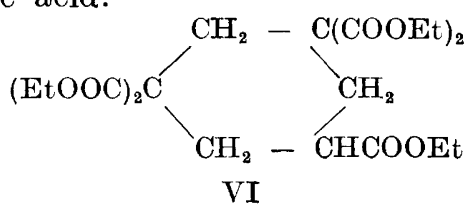

A small amount of diethyl carbonate was isolated. No compound belonging to the cyclobutane series could be found.

3. The reaction between 1,1,4,4-tetracarbethoxybutane and methylene bromide. The investigation of this reaction confirmed the results of Pospischill ${ }^{5}$, Thole and Thorpe ${ }^{6}$, Perkin and Scarborough ${ }^{7}$, and Guha and Ranganathan ${ }^{8}$. The yield of IV, $\mathrm{n}=2$, was poor and considerable amounts of tarry by-products were obtained as the above authors also have found. A small amount of diethyl carbonate, which probably resulted from the reaction between $1,1,4,4$ tetracarbethoxybutane and ethoxide ion ${ }^{10}$, was isolated. IV, $\mathrm{n}=2$, has been found to be stable under the reaction conditions employed ${ }^{6}$.

4. The reaction between 1,1,5,5-tetracarbethoxypentane and methylene bromide. Perkin's ${ }^{9}$ results were fully confirmed and only IV, $\mathrm{n}=3$, could be isolated. No diethyl carbonate was found.

\section{DISCUSSION}

At first the reaction between 1,1,3,3-tetracarbethoxypropane and a methylene halide will be considered, as it deviates from the normal behaviour. Meerwein and Schürmann ${ }^{11}$ have shown that 1,1,3,3-carbomethoxypropane reacts with sodium methylate in methanol in a complex manner with the formation of a bicyclononane derivative. They were also able to demonstrate the intermediate steps of the reaction and that the same products were obtained irrespective of whether the starting materials were sodium methoxide and 1,1,3,3-tetracarbomethoxypropane, sodium methoxide, 1,1,3,3-tetracarbomethoxypropane, and dimethyl methylenemalonate or sodium methoxide, methylene iodide, and dimethyl malonate.

The formation of pentaethyl cyclohexane-1,1,3,3,5-pentacarboxylate can be easily explained on the basis of Meerwein and Schürmann's investigations in the following way: In an alkaline medium 1,1,3,3-tetracarbethoxypropane is in equilibrium with a mixture of diethyl methylenemalonate and diethyl malonate.

$$
(\text { EtOOC })_{2} \mathrm{CHCH}_{2} \mathrm{CH}(\mathrm{COOEt})_{2} \rightleftharpoons \mathrm{CH}_{2}=\mathrm{C}(\mathrm{COOEt})_{2}+\mathrm{CH}_{2}(\mathrm{COOEt})_{2}
$$

Diethyl methylenemalonate then reacts with 1,1,3,3-tetracarbethoxypropane (a Michael addition) according to the formula:

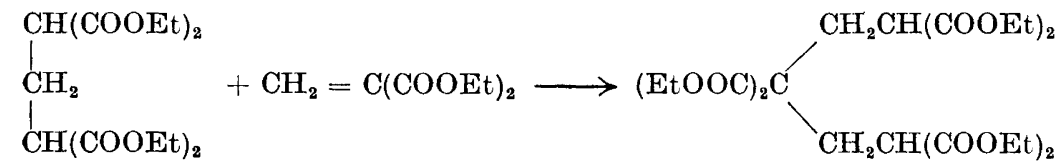

Acta Chem. Scand. 12 (1958) No. 4 
$1,1,3,3,5,5$-hexacarbethoxypentane is formed as has been proved by Meerwein and Schürmann in the case of the methyl derivative and is cyclized with the excess of methylene halide with the formation of VI and the elimination of one carbethoxy group as diethyl carbonate.

In the previous paper dealing with this subject ${ }^{2}$, a reaction scheme for the reaction between a monosubstituted malonic ester and a methylene halide was proposed. It can be summarized in the following way:

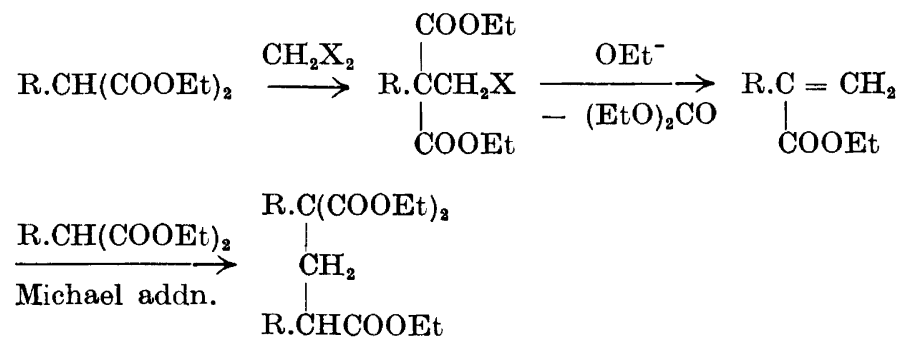

Apparently this mechanism is not always valid when the two malonic ester residues are situated within the same molecule. However, the first step must be the formation of a bromomethyl-substituted compound VII.

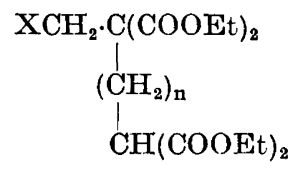

VII

The second step may take place either according to the above mechanism via an unsaturated compound (elimination of one carbethoxy group to form V) or the halogen atom may be displaced directly by reaction with the second anionic center. Actually both situations have been observed (formation of compound VI and compound IV, $\mathrm{n}=0,2,3$ ), but it is difficult to draw any conclusions from the above data regarding the structural features which determine the course of the reaction. The second mechanism is rather remarkable as it involves displacement of a halogen atom under normal conditions in a structure analogous to the neopentyl halides ${ }^{12}$. Probably this is a manifestation of the well known but not entirely understood effect, that accommodation of substituents at the ends of a closing carbon chain facilitates ring formation.

\section{EXPERIMENTAL}

Tetraethyl cyclopropane-1,1,2,2-tetracarboxylate. Sodium, $9.2 \mathrm{~g}$ (0.4 mole), was dissolved in $150 \mathrm{ml}$ of absolute ethanol, and $63.6 \mathrm{~g}(0.2 \mathrm{~mole})$ of 1,1,2,2-tetracarbethoxyethane were added whereby a stiff porridge of its disodium compound was obtained. Methylene bromide, $34.8 \mathrm{~g}(0.2 \mathrm{~mole})$, was added and the mixture was held at reflux temperature for $20 \mathrm{~h}$. After this time the mixture was thinly fluid and almost neutral. It was neutralized with a few drops of glacial acetic acid and the ethanol was distilled off 
through a short column. Water was added and the semi-solid mass was taken up in ether, the ether solution dried with anhydrous magnesium sulphate, and finally the ether distilled off. Distillation of the residue yielded $48.5 \mathrm{~g}(71 \%)$ of tetraethyl cyclopropane1,1,2,2-tetracarboxylate, which soon solidified. It could eventually be recrystallized from a mixture of absolute ether and petroleum ether and then melted at $41-43^{\circ} *$. No diethyl carbonate could be detected in the fore-runs.

When the same procedure was repeated with methylene iodide instead of the bromide the reaction mixture became entirely clear after refluxing over night. After neutralization with a few drops of glacial acetic acid, the ethanol was distilled off and water was added. In this case the reaction product solidified completely and could be filtered off. After drying in a vacuum-desiccator it was recrystallized from a mixture of absolute ether and petroleum ether, m. p. $41-43^{\circ}$. The yield was $72 \%$. (Found: C 54.2; H 6.7. Calc. for $\mathrm{C}_{15} \mathrm{H}_{22} \mathrm{O}_{8}$ : C 54.5; $\mathrm{H}$ 6.7). Kötz and Stalmann ${ }^{3}$ reported m. p. $43^{\circ}$. Guthzeit and Dressel 4 also reported m. p. $43^{\circ}$ for a specimen prepared from 1,1,3,3-tetracarbethoxypropane and bromine.

The tetraethyl ester was hydrolyzed by boiling with $10 \%$ ethanolic potassium hydroxide over night. The ethanol was evaporated on the water-bath and the residue treated with dilute hydrochloric acid. The resulting solution was evaporated to dryness on the water-bath (the tetraacid is sufficiently stable to permit this operation) and the residue repeatedly extracted with boiling acetone. The combined acetone extracts were concentrated to a small volume and left to crystallize. An $81 \%$ yield of rather pure tetraacid was obtained. After recrystallization from acetone it melted at $205-210^{\circ}$ (decomp.). (Found: $\mathrm{C}$ 38.7; $\mathrm{H} \mathrm{2.8}$. Calc. for $\mathrm{C}_{7} \mathrm{H}_{6} \mathrm{O}_{8}$ : C 38.5; $\mathrm{H}$ 2.8). Guthzeit and Dressel ${ }^{4}$ reported m. p. $200^{\circ}$ (decomp.).

Pentaethyl cyclohexane-1,1,3,3,5-pentacarboxylate. Sodium, $11.5 \mathrm{~g}$ (0.5 mole), was dissolved in $180 \mathrm{ml}$ of absolute ethanol and the solution poured into a soda-water bottle together with $83.0 \mathrm{~g}(0.25 \mathrm{~mole})$ of $1,1,3,3$-tetracarbethoxypropane and $67.0 \mathrm{~g}(0.25 \mathrm{~mole})$ of methylene iodide. When the first reaction had subsided (after about 5 min) the bottle was sealed and heated in a water-bath at $100^{\circ}$ for $30 \mathrm{~h}$. The reaction mixture, which was almost neutral was worked up as in the foregoing experiment. Distillation in vacuo yielded one fraction $(2.8 \mathrm{~g})$ boiling at $50-60^{\circ} / 50 \mathrm{~mm}$, which consisted of diethyl carbonate, one fraction boiling up to $210^{\circ} / 4 \mathrm{~mm}$, and one main fraction at $210-215^{\circ} / 4 \mathrm{~mm}$. The second fraction, which weighed $19.5 \mathrm{~g}$, boiled inconstantly through the whole interval and gave on acid hydrolysis a small amount of a substance with m. p. $235-240^{\circ}$. It was readily oxidized with alkaline potassium permanganate but was not further investigated. No other definite compounds were found among the hydrolysis products.

The third fraction $(33.8 \mathrm{~g})$ consisted of pentaethyl cyclohexane-1,1,3,3,5-pentacarboxylate, as indicated by the analysis and its behaviour upon hydrolysis. (Found: C 56.4; $\mathrm{H}$ 7.3. Calc. for $\mathrm{C}_{21} \mathrm{H}_{32} \mathrm{O}_{10}$ : C 56.7; $\mathrm{H}$ 7.3.)

The pentaethyl ester, $20.0 \mathrm{~g}$, was hydrolyzed by boiling over night with $10 \%$ ethanolic potassium hydroxide. The ethanol was removed on the water-bath and the residue was treated with dilute hydrochloric acid. The solution was then continuously extracted with ether for two days. The ether solution, which gradually deposited large amounts of crystals, was filtered and the mother liquor was evaporated to dryness, whereby a second crop of crystals was obtained. The total yield of crude product was $12.1 \mathrm{~g}(88 \%)$. The crystals were somewhat sticky. A pure product was obtained after recrystallization from hot $\left(80^{\circ}\right)$ glacial acetic acid, though with considerable loss of substance. The m. p. was $180-184^{\circ}$ (decomp.). The substance had to be dried at $110^{\circ}$ for $2 \mathrm{~h}$ before analysis.

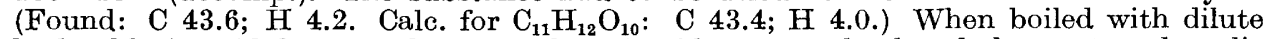
hydrochloric acid for some hours, carbon dioxide was evolved and the pentacarboxylic acid converted to cyclohexane-1,3,5-tricarboxylic acid, m. p. 208-213 (se日 below).

The pentaethyl ester, $5.0 \mathrm{~g}$, was boiled over night with concentrated hydrochloric acid. The solution was evaporated to dryness on a water-bath and an almost quantitative yield of crude cyclohexane-1,3,5-tricarboxylic acid was obtained, m. p. $205-210^{\circ}$. It was recrystallized twice from a mixture of benzene and acetone and then melted at $212-$ $215^{\circ}$. Before analysis it had to be dried at $110^{\circ}$ for $2 \mathrm{~h}$ in order to remove traces of solvent, which was held firmly by the crystals. (Found: C 49.9; H 5.7; equiv. wt. 73.0. Calc. for $\mathrm{C}_{9} \mathrm{H}_{12} \mathrm{O}_{6}$ : $\mathrm{C}$ 50.0; $\mathrm{H}$ 5.6; equiv. wt. 72.1.) The acid was converted into its triamide accord-

* The melting points were determined with a Kofler apparatus.

Acta Chem. Scand. 12 (1958) No. 4 
ing to Newman and Lowrie ${ }^{13}$, m. p. $286-289^{\circ}$ (decomp.) after recrystallization from water, and to its trimethyl ester by esterification with methanol, m. p. $43-45^{\circ}$ after recrystallization from petroleum ether. Newman and Lowrie reported for the acid $\mathrm{m}$. p. $216-218^{\circ}$, the amide $287.5-288.5^{\circ}$ (decomp.), and the methyl ester $48-49^{\circ}$.

If methylene bromide was used instead of the iodide and the reaction carried out at $100^{\circ}$ for $30 \mathrm{~h}$, the same products were obtained.

Tetraethyl cyclopentane-1,1,3,3-tetracarboxylate. Sodium, $4.6 \mathrm{~g}$ (0.2 mole), was dissolved in $70 \mathrm{ml}$ of absolute ethanol and $34.6 \mathrm{~g}(0.1$ mole) of 1,1,4,4-tetracarbethoxybutane together with $17.4 \mathrm{~g}(0.1$ mole) of methylene bromide were added during a few minutes. The mixture was boiled under reflux for $20 \mathrm{~h}$, after which time it was almost neutral. It was worked up as usual. The crude product was not distillable even at low pressures without extensive decomposition, and therefore it was hydrolyzed directly. However a small amount (1.2 g) of diethyl carbonate was distilled off, b. p. $50-60^{\circ} / \mathrm{ca} .50 \mathrm{~mm}$.

The crude ester (30.2 g) was boiled with $10 \%$ ethanolic potassium hydroxide over night. The ethanol was distilled off and dilute hydrochloric acid was added. The solution was continuously extracted with ether for $36 \mathrm{~h}$. The ether solution gradually deposited crystals which were filtered and dried, m. p. $185-190^{\circ}$ (decomp.). The substance (4.3 g) was cyclopentane-1,1,3,3-tetracarboxylic acid as indicated by analysis. (Found: $\mathrm{C} 44.0$;

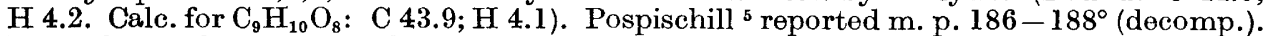
From the mother liquor of the above filtration a dark viscous oil was obtained. No definite compounds could be isolated from this oil.

Tetraethyl cyclohexane-1,1,3,3-tetracarboxylate. Sodium, $9.2 \mathrm{~g}(0.4$ mole $)$, was dissolved in $150 \mathrm{ml}$ of absolute ethanol. To the solution were added $72.0 \mathrm{~g}(0.2$ mole) of $1,1,5,5-$ tetracarbethoxypentane and then dropwise $34.8 \mathrm{~g}(0.2 \mathrm{~mole})$ of methylene bromide. A vigorous reaction soon set in and when it had subsided the mixture was boiled under reflux for $20 \mathrm{~h}$. The mixture then was almost neutral and was worked up in the usual manner. The crude product $(68.3 \mathrm{~g})$ which did not contain any detectable amounts of diethyl carbonate, could not be distilled without decomposition, even at low pressures. It was therefore directly hydrolyzed with $10 \%$ potassium hydroxide over night and the tetraacid was isolated by means of continuous ether-extraction as above. A yield of $16.4 \mathrm{~g}$ of a rather pure product was obtained. It was recrystallized from hot $\left(80^{\circ}\right)$ water and then melted at $210-220^{\circ}$ (decomp.). (Found: $\mathrm{C} 46.3 ; \mathrm{H}$ 4.7. Calc. for $\mathrm{C}_{10} \mathrm{H}_{12} \mathrm{O}_{8}$ : $\mathrm{C} 46.2$; H 4.7.) Perkin ${ }^{9}$ reported $\mathrm{m}$. p. 218-220. The mother liquors were examined for other compounds but without success.

The author wishes to express his sincere gratitude to Professor Erik Larsson for his kind interest in this work. A grant from Kungliga Fysiografiska Sällskapet is gratefully acknowledged.

\section{REFERENCES}

1. Eberson, L. Acta Chem. Scand. 9 (1956) 1711.

2. Eberson, L. Acta Chem. Scand. 12 (1958) 314.

3. Kötz, A. and Stalmann, G. J. prakt. Chem. 68 (1903) 156.

4. Guthzeit, M. and Dressel, O. Ann. 256 (1890) 171.

5. Pospischill, K. T. Ber. 31 (1898) 1950.

6. Thole, F. B. and Thorpe, J. F. J. Chem. Soc. 99 (1911) 2183.

7. Perkin, W. H. and Scarborough, H. A. J. Chem. Soc. 119 (1921) 1400.

8. Guha, P. C. and Ranganathan, S. K. Ber. 69 (1936) 1199.

9. Perkin, W. H. J. Chem. Soc. 59 (1881) 798.

10. Lean, B. A. J. Chem. Soc. 65 (1894) 995.

11. Meerwein, H. and Schürmann, W. Ann. 398 (1913) 196.

12. Newman, M. S. Steric Effects in Organic Chemistry, Wiley \& Sons, Inc., New York 1956 , p. $76 \mathrm{ff}$.

13. Newman, M. S. and Lowrie, H. S. J. Am. Chem. Soc. 76 (1954) 4598.

Received February 22, 1958. 